\title{
Doğrusal Olmayan Kanonik Korelasyon Analizi ile Seçilmiş Demografik ve Sosyo-Kültürel Kavramların Değerlendirilmesi
}

\begin{abstract}
Doğrusal Olmayan Kanonik Korelasyon Analizi ile Seçilmiş Demografik ve Sosyo-Kültürel Kavramların Değerlendirilmesi

Öz

Bu çalışmanın amacı, kategorik değişken gruplarının değerlendirilmesinde kullanılan önemli yöntemlerden biri olarak bilinen Gifi terminolojisinin son aşaması olan doğrusal olmayan kanonik korelasyon analizinin (OVERALS) kullanımıdır. Bu amaçla, Türkiye'deki bireylerin, seçilen demografik ve sosyo-kültürel kavramlar açısından farklılık gösterip göstermedikleri değerlendirilmiştir. Çalışmada, öncelikle OVERALS hakkında gerekli genel bilgiler verilmiştir. Sonrasında, veriler SPSS 24.0 paket programı ile test edilmiştir. Araştırma için, Türkiye İstatistik Kurumu (TÜiK) tarafından her yıl gerçekleştirilen yaşam memnuniyeti anketinin 2017 mikro verileri kullanılmış ve 9876 adet geçerli anket verisinden faydalanılmıştır. OVERALS sonuçlarına göre, bitirilen okul, cinsiyet, bilim, moda, ekonomi, spor ve kültür kavramlarının, Türkiye'de demografik ve sosyo-kültürel açıdan ayırma gücü yüksek değişkenlerdir. Çalışmada hangi demografik ve sosyo-kültürel kavramlar arasında toplumsal benzerlik ya da farklılıklar olduğu da değerlendirilmiştir.
\end{abstract}

Anahtar Kelimeler: Doğrusal Olmayan Kanonik Korelasyon Analizi, OVERALS, Çok Değişkenli İstatistiksel Analiz, Nicel Karar Yöntemleri Evaluation of Selected Demographic and Socio-Cultural
Concepts by Nonlinear Correlation Analysis

\begin{abstract}
The aim of this study is the use of nonlinear canonical correlation analysis (OVERALS), which is the final stage of Gifi terminology, which is known as one of the important methods used in the evaluation of categorical variable groups. For this purpose, individuals in Turkey were evaluated to see whether they differentiated or not, in terms of selected demographic and socio-cultural concepts. In this study, firstly general information about OVERALS is given. Afterwards, data were tested with the SPSS 24.0 package program. For this research, life-satisfaction survey 2017-microdata which are conducted every year by Turkey Statistical Institute (TSI) were used; and 9876 valid survey data were handled. According to OVERALS results, graduated school, gender, science, fashion, economy, sports and culture are strong variables which have high power of separation in terms of demographic and socio-cultural concepts in Turkey. Similarities and differences between demographic and socio-cultural concepts are also evaluated.
\end{abstract}

Keywords: Nonlinear Canonical Correlation Analysis, OVERALS, Multivariate Statistical Analysis, Quantitative Decision Techniques

\section{Giriş}

OVERALS, aynı anda birçok veri setinin analiz edilebilmesini sağlayan istatistiksel bir tekniktir. Özellikle bu amaç için geliştirilmemiş olsa da, birbirinden farklı birçok çoklu veri tablosu bu yöntemle analiz edilebilmektedir (Van der Burg, De Leeuw ve Dijksterhuis, 1994: 141). Araştırılacak veri setleri sayısal ölçme değerlerinden oluşuyor ise kanonik regresyon kullanımı veri analizi için daha uygunken, veri setleri içinde sıralı (ordinal) değişkenler bulunduğunda doğrusal olmayan kanonik korelasyon analizi (OVERALS) veri analizi için daha uygundur. OVERALS, kategorik değişkenlere uygulanabildiğinden işletme, üretim yönetimi, tıp, psikoloji, ulaşım ve meteoroloji gibi içinde kategorik değişkenler barındıran birçok disiplinde kullanılabilmektedir (Filiz ve Kolukısaoğlu, 2012: 60).

\footnotetext{
${ }^{1}$ Dr. Öğr. Üyesi, Giresun Üniversitesi, i.i..B.F., İşletme Bölümü, mustafa.ozkan@giresun.edu.tr. Yazar ORCID bilgisi: http://orcid.org/0000-0002-4439-2531.
} 
OVERALS ile iki ya da daha fazla değişken seti arasındaki korelasyon incelenip, veri setlerinin birbirlerine ne kadar benzediği değerlendirilmektedir (Bayram ve Ertaş, 2001). Kategorik değişken setlerine yönelik problemlerin çözümlenmesinde kullanılan yöntem, değişkenlerin birbirleriyle ilişkilerinin grafiksel gösterimine olanak sağlaması gibi bir avantaja da sahiptir. Ancak yöntemin dezavantajı ise veri ölçüm düzeylerinde farklılıklar olduğunda, değişkenlerin dağılım farklılı̆ı ve değişkenler arasında var olan ilişkilerin doğrusallığı hakkında bilgi vermemesidir (Özer ve Özden, 2013: 73-74).

Bu çalışmada, ilk önce literatür taraması yapılmış, sonrasında yöntembilim kısmında homojenlik analizi (HOMALS) ve doğrusal kanonik korelasyon analizinden (CANALS) bahsedilmiştir. Daha sonra, OVERALS hakkında genel bilgiler verilmiştir. Son olarak Türkiye İstatistik Kurumu (TÜiK)-Yaşam memnuniyeti anketinin 9876 veriden oluşan 2017 mikro verileri kullanılarak bir uygulama gerçekleştirilmiştir. Elde edilen analiz sonuçları değerlendirilmiştir.

\section{Literatür Taraması}

Yerli ve yabancı literatür incelendiğinde, OVERALS ile ilgili farklı disiplinlerde yapılmış çeşitli çalışmalara ulaşmak mümkündür. Hsieh (2001), Tropikal Pasifik deniz seviyesi basıncı ve deniz yüzeyi sıcaklığı arasındaki ilişkiyi OVERALS ile değerlendirmiş ve anlamlı farklılıklar bulmuştur. Bayram ve Ertaş (2001), temel bileşenler analizi ve OVERALS ile Bursa ilinin hane halkı tüketim harcamaları verilerini kullanarak, tüketici harcama düzenleri için tüketici karakteristiği oluşturmak amacıyla homojen bir hane halkı profili belirlemeye çalışmışlardır. Girginer vd. (2007), ise iktisat, işletme ve maliye programı öğrencilerinin istatistik dersi için tutumlarını çeşitli demografik değişkenler ve istatistik tutum ölçeğiyle bütünleştirmişlerdir. Sonrasında da OVERALS ile bu setleri değerlendirmişlerdir. Çalışma sonuçlarına göre, öğrencilerin ders tekrar sayıları, başarı oranları ve tekrar nedenleri ile derse ait tutumları arasında anlamlı ilişkiler bulmuşlardır. Frie ve Janssen (2009), sosyo-ekonomik durum, yaşam koşulları, yaşam tarzları, sağlıkla ilgili davranış ve sağlıkla ilgili değişkenleri kullandıkları çalışmalarında; katılımcıların bu değişkenlere göre farklılaşıp, birbirlerine göre ayırt edilebilirliğini belirlemek için OVERALS kullanmışlardır. Çalışmalarında, sağlık özelliklerinin sosyo-ekonomik koşullar ve yaşam tarzları ile birlikte analiz edilebilir olduğunu ve karmaşık korelasyon ilişkilerinin daha kolay yorumlanabilir olduğunu görmüşlerdir. Sertbarut (2010), Türk bankacılık sektöründeki karlılığı incelemek amacıyla yaptığı çalışmasında, hem doğrusal hem de doğrusal olmayan kanonik korelasyon analizi kullanmıştır. Giray (2011), TÜik- Yaşam Memnuniyeti Anketi mikro verilerini kullanarak, bireysel sosyo-demografik özelliklerle mutluluk algısı arasındaki yapıyı OVERALS ile değerlendirmiştir. Filiz ve Kolukısaoğlu (2012), bir hizmet işletmesi üzerinde gerçekleştirdikleri çalışmalarında, müşteri memnuniyet düzeyini ve müşteri memnuniyetine etki eden değişkenleri OVERALS ile değerlendirmişlerdir. Bülbül ve Giray (2012), iş yaşamı ile özel yaşam memnuniyeti arasında bir ilişki olup olmadığını, eğer böyle bir ilişki varsa da ilişkinin seviyesini belirlemek amacıyla, Tüik-Yaşam Memnuniyet Anketi mikro verilerini OVERALS ile değerlendirmişlerdir. Çalışmalarında, iş yaşamı ve özel yaşam memnuniyeti arasındaki ilişki seviyesini \%66 olarak hesaplamışlar ve buna bağlı çeşitli değerlendirmeler yapmışlardır. Özer ve Özden (2013), yaş meyve sebze ihracatçısı pilot firmaların temel özellikleri ile söz konusu firmaların aralarında farklııklara neden olan etmenleri belirlemek için OVERALS kullanmış ve anlamlı farklılıklar tespit etmişlerdir. Aydın vd. (2014), öğrencilerin demografik özellikleri ile eğitimden duydukları memnuniyet düzeyleri arasındaki ilişkiyi OVERALS ile incelemişlerdir. Dong vd. (2015), OVERALS için çeşitli veri kümeleri arasındaki doğrusal veya doğrusal olmayan ilişkileri otomatik olarak yakalayabilen, eigenspace mak- 
simum bilgili kanonik korelasyon analizi (emiCCA) olarak adlandırdıkları denetimsiz ve veri güdümlü yeni bir yöntem geliştirmişlerdir. Hsieh vd. (2017), yaşlıların demografik özellikleri, uzun süreli bakım olanakları ve bu amaçlı bakım tesislerine geçiş nedenleri arasındaki ilişkileri araştırmak amacıyla, benzer kategorik değişkenler arasındaki ilişkileri OVERALS ile değerlendirmişlerdir.

\section{Metodoloji}

OVERALS, ilk kez 1981 yılında Gifi ve 1984 yılında Van der Burg, De Leeuw ve Verdagaal tarafından matematiksel altyapısı oluşturularak, aynı kısaltma ile literatüre kazandırılmıştır. Yöntem, temelde doğrusal kanonik korelasyon analizinin özel bir formudur (Van Der Burg vd., 1994: 141). Gifi gerçek bir kişi değil, Leiden Üniversitesi'nde Jan De Leeuw liderliğindeki bir grup araştırma grubunun takma adıdır. Gifi karakteri, Bert Betonville, Steef de Bie, Eekevan der Burg, John Van de Geer, Willem Heiser, Judy Knip, Jan De Leeuw, Jacqueline Meulman, Peter Neufeglise, André Nierop ve Ineke Stoop ismindeki araştırmacılardan oluşmaktadır. Orijinal olarak Leiden Üniversitesi'nde geliştirilen Gifi terminolojisi, birçok alanda kullanılan OVERALS, PRINCALS, HOMALS, CANALS, MORALS, MANOVALS, CRIMINALS, PARTALS ve PATHALS kIsaltmalarıyla bilinen çeşitli istatistiksel analizlerin ve bilgisayar programlarının temelini oluşturmaktadır. Bu programlardan ilki IBM-SPSS paket programı modülünde, Gifi terminolojisindeki HOMALS kısaltması ile bilinen çoklu homojenlik analizidir (Van der Heijden ve Van Buuren, 2016: 2-3; De Leeuw vd., 2016). HOMALS, Gifi terminolojisindeki doğrusal olmayan çok değişkenli analizlerinin temelini oluşturur. Burada "HOM" homojenlik ve "ALS" ise hesaplamanın yapıldığı "dalgalı/alternatif en küçük kareler (Alternating Least Squares)" tekniğinin kısaltmasıdır (Van de Geer'den aktaran Altaş ve Giray, 2013: 138). HOMALS, verileri herhangi bir ölçüm seviyesinde nominal, ordinal veya aralıklı değişkenler olabilen " $n$ " adet gözlem üzerinde ölçülen, "kategorik değişkenler seti" oluşturulması ile başlar. Dalgalı en küçük kareler yöntemini ise algoritmanın hesaplanmasında kullanır (Van der Heijden ve Van Buuren, 2016: 3). Yöntem, çok değişkenli bir veri setinin değişkenleri arasındaki korelasyonları, en uygun ölçeklendirme ile maksimize etmeyi amaçlar (De Leeuw ve Mair, 2009: 1). Aslında, tüm Gifi terminolojisi temelde kayıp fonksiyonu problemi üzerine inşa edilmiştir ve bu minimizasyon probleminin farklı çözüm versiyonlarından oluşur (Michailidis ve De Leeuw, 1998: 308). Çözüme getirilen her bir ek kısıt, Gifi terminolojisini genişletir. OVERALS da, Gifi terminolojisinin diğer alt sistemleri gibi HOMALS'ın özel bir formudur ve HOMALS üzerine inşa edilmiştir. Ayrıca Gifi terminolojisinin en genel modeli olarak kabul edilir (De Leeuw, 1984: 415; Van der Burg vd., 1994: 141). Bu sebeple, çalışmada öncelikle kısaca HOMALS'a yer verilmiştir.

\subsection{Homojenlik Analizi}

HOMALS, değişkenlerin her birinin kategorilerinin homojenliğini en üst düzeye çıkaracak şekilde miktarlarını veya dönüşümlerini belirler (Van der Burg vd., 1988: 178). Literatüre ilk kez HOMALS olarak girse de ilerleyen yıllarda bu ismi terk edilmiş ve "Çoklu Uygunluk Analizi (Multiple Correspondence Analysis)" ismi tercih edilmiştir (Suner ve Çelikoğlu, 2010: 45). Yöntemin çözümünde farklı yaklaşımlar olsa da Michailidis ve De Leeuw tarafından geliştirilen geometrik çözümleme literatürde fazlasıyla dikkat çekmiştir. Çalışmalarında, yedi nesnesi bulunan 4×3'lük intimal tablosuna karşılık gelen bir örneğin iki bölümlü grafik gösterimini kullanmışlardır. 
Şekil 1: Michailidis ve De Leeuw HOMALS Örneği

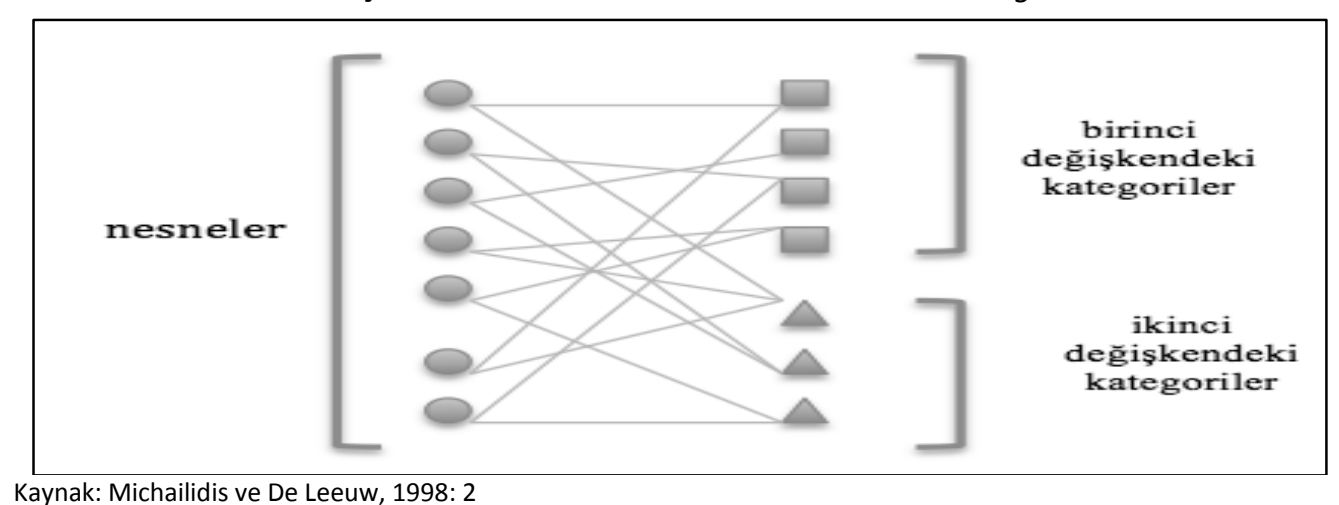

Geometrik olarak HOMALS, $X$ 'lerin nesne ve $Y$ 'lerin kategori olarak kabul edildiği bir Öklid uzayında, kayıp fonksiyonun düşük boyutlu ortak bir haritasını oluşturması amacıyla geliştirilmiştir. Bu amaca ise;

$$
\sigma\left(X ; Y_{1}, \ldots Y_{J}\right)=J^{-1} \sum_{j=1}^{J} S S Q\left(X-G_{j} Y_{j}\right)=J^{-1} \sum_{j=1}^{J} \operatorname{tr}\left(X-G_{j} Y_{j}\right)^{\prime} \cdot\left(X-G_{j} Y_{j}\right)
$$

olarak ifade edilen kayıp fonksiyonunun minimize edilmesiyle ulaşılmaktadır. Burada;

$X: \mathbb{R}^{p}$ genişliğinde bir Öklid uzayında nesne köşe noktalarını içeren $N \times p^{\prime}$ lik bir matrisi,

$Y_{j}: Y_{j}(j \in J$ ve $J=\{1,2,3, \ldots, J\})$ veya kısaca $\ell_{j}$ olarak bilinen, pozitif verilerden oluşan $\ell_{j} \times p$ 'lik bir matriste $j$. verinin kategorik köşelerini temsil eden bir matrisi,

$G_{j}$ :Eğer $i$. nesne kategori t'ye aitse $G_{j}(i, t)=1$ olarak veya $i$. nesne herhangi başka diğer kategorilere aitse $\left(i=1,2,3 \ldots, n, t=1,2,3 \ldots, \ell_{j}\right) G_{j}(i, t)=0$ olarak kabul edilen gösterge matrislerini,

SSQ : $S S Q(\Re)=\mathfrak{R}$ matrisi elemanlarının kareleri toplamını,

G : Aslında ikili (bipartite) grafiğin basitçe bitişik matrisi olan $G=\left(G_{1}, G_{2}, G_{3}, \ldots, G_{j}\right)$ matrisini ifade etmektedir

Formül (1)'de, $X$ 'e nesne skorları matrisi, $Y_{j}$ 'ye kategori sayısallaştırmaları matrisi ve $G_{j}$ ' ye gösterge matrisi denir. Ayrıca, eşitliğin çözümünde $X$ ve $Y_{j}$ değerlerinin 0 (sıfır) sonucu almasına ve böylece anlamsız çözümler ortaya çıkmasına engel olmak için, modele normalizasyon kısıtları denilen;

$$
x^{\prime} X=n I_{p}
$$

ve

$$
u_{n}^{\prime} X=0
$$


Kısıtlar eklenir. Formül (2) ve formül (3)'te görülen normalizasyon kısıtlarındaki $u^{\prime}$, elemanları 1 olan $(1 \times n)$ boyutlu bir vektördür.

Formül (1)'de, her bir nesnenin diğer tüm değişkenlerin ilgili kategorileri ile bir bağlantısı olduğu kabul edilir. Bu bağlantı ise Öklid uzayında iki nesne arasındaki kenar uzunluklarını temsil eder. Bu kenar uzunluklarının kareleri toplamlarını en küçükleyen grafiğin çizimi gerçekleştirilirse problem minimize edilmiş olacaktır (Michailidis ve De Leeuw, 1998: 307-308). Burada, iki kenar arasındaki uzaklık $\mathfrak{R}=X-G_{j} Y_{j}$ formülü ile hesaplanır (Giray, 2011: 66 ).

\subsection{Doğrusal Kanonik Korelasyon Analizi}

Doğrusal modeller ailesinin bir üyesi olan ve Hotelling tarafından 1935 yılında ortaya atılan doğrusal kanonik korelasyon analizi (CANALS), çok değişkenli varyans analizi (MANOVA) ve faktör analizine oranla başlangıçta daha az kullanım sıklığına sahip olan karmaşık çok değişkenli prosedürdür (Meyers vd., 2009: 345). CANALS, $p>1$ ve $q>1$ sayıda değişken bulunduran iki veri setindeki değişkenler arası ilişkileri ortaya koymaktadır (Filiz ve Kolukısaoğlu, 2012: 52). Literatürde geleneksel CANALS modeli, farklı kaynaklarda farklı isimlerle anılmıştır. Modelin önüne klasik ve geleneksel gibi farklı sıfatlar eklense de, hepsi doğrusal modeli temsil etmektedir. Aksi belirtilmemişse kanonik ifadesi, modelin doğrusal olduğunun anlaşılması için yeterlidir. Yöntem, iki rastgele değişkenli veri setini, maksimum korelasyon elde edilecek şekilde doğrusal çıkıntı vektörleri ile optimize eder (Yoshida vd., 2017: 2). Bu iki setten biri bağımsız değişkenlerden oluşurken, diğeri ise bağımlı değişkenlerden oluşmaktadır (Thompson, 1984: 9).

Yıllar içerisinde kullanım sıklığı artan CANALS, kanonik işlevlerin gerçekleştiği istatistiksel tahmin derecesini optimize etmesi sebebiyle, prosedürü tartışılmasına rağmen uygulanmakta ve teorik çerçevesi sürekli güncellenmektedir (Meyers vd., 2009: 345). CANALS ile aşağıda listelenen sorular hakkında bilgi edinilebilmektedir (Thompson, 1984: 9-10; Çankaya, 2005: 24-25).

- Iiki veya daha fazla değişkenden oluşan bir setin, bir başka iki veya daha fazla değişkenden oluşan set tarafından ne ölçüde tahmin edilebilir veya açıklanabilir?

- Tek bir değişken, değişkenin ait olduğu setin açıklayıcı gücüne ne kadar katkıda bulunur?

- Tek bir değişken, değişkenin ait olmadığı diğer setteki değişkenlerin bileşimini öngörmeye veya açıklamaya ne ölçüde katkıda bulunur?

- Bir değişken setinin, diğer değişken setinin farklı bölümlerini farklı şekillerde "açıklayabilme" becerisinde hangi dinamikler yer alır?

- Farklı kanonik işlevlerin, ilişkileri öngörmek veya açıklamak için göreceli gücü ne kadardır?

- Örneklerde veya örnek alt gruplarında kanonik sonuçlar ne kadar kararlıdır?

- Elde edilen kanonik sonuçlar, beklenen kanonik sonuçlara ne kadar yakındır?

- Aynı ana kütleden elde edilmiş olan iki değişken seti birbirlerinden bağımsız mıdır?

- Bağımlı ve bağımsız değişken setlerindeki değişkenler arasında var olan korelasyonu en yüksek düzeye ulaştıran doğrusal kombinasyonun nedir?

CANALS'ın önemli avantajlarının başında,oluşturulan hipotezde I. tip hata yapılmasının önüne geçmesi gelmektedir (www.mvstats.com). CANALS'ın varsayımları şunlardır (Keskin ve Özsoy, 2004: 68); 
- Veriler çok değişkenli normal dağılıma sahip olmalıdır.

- Verilerin ölçümünde minimum hata olmalıdır.

- Değişkenler arasında çoklu bağıntı olmamalıdır.

- Örneklem mümkün olduğunca büyük olmalıdır (değişken sayısının en az 5 katı kadar).

CANALS çözüm aşaması, kayıp fonksiyonu ile formül (4)'teki gibi ifade edilir (Giray, 2011: 98102);

$$
\min \sigma_{m}(X, A)=K^{-1} \sum_{k} S S Q\left(X-H_{k} A_{k}\right)
$$

Burada;

$X \quad$ : Nesne skorları matrisini,

$H_{k}$ :Orijinal veri setinden elde edilmiş, k. değişken setini gösteren $\left(n \times J_{k}\right)$ boyutlu matrisini,

$A_{k}$ : Çoklu çözüm durumunda ağılık katsayılarını gösteren $\left(j_{k} \times p\right)$ boyutlu matrisini,

$S S Q$ : Vektör ya da matrislerin köşegen elemanlarının karelerinin toplamını,

$m$ : Toplam değişken sayısını,

$k \quad$ : Set (küme) sayısını ifade etmektedir.

Kanonik değişkenler, $(n \times K)$ boyutlu $Z$ matrisinde bir araya getirilir. $Z$ matrisinin korelasyon matrisi ise $R(Z)$ olarak gösterilir ve optimallık kriterlerinin çoğu bu korelasyon matrisinin fonksiyonlarıdır. $H_{k} A_{k}$, veri setlerinin doğrusal kombinasyonudur ve çoklu çözüm durumunda, $Z_{k}=H_{k} A_{k}$ kabul edilir. Bu ifade;

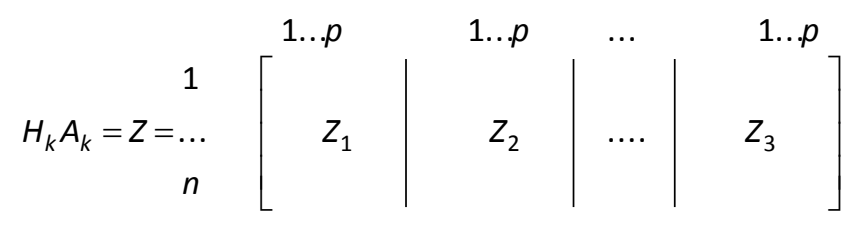

$\left(n \times K_{p}\right)$ boyutlu matristir. $Z_{1}, Z_{2}, \ldots Z_{k}$ matrisleri ise alt matrislerdir. Kanonik değişkenleri gösteren matris ise $\left(K_{p} \times K_{p}\right)$ boyutlu matristir.

$$
R(Z)=\left[\begin{array}{ccccc}
R_{11} & R_{12} & R_{13} & \ldots & R_{1 K} \\
R_{21} & R_{22} & R_{23} & \ldots & R_{2 K} \\
R_{31} & R_{32} & R_{33} & \ldots & R_{3 K} \\
\ldots & \ldots & \ldots & \ldots & \ldots \\
R_{K 1} & R_{K 2} & R_{K 3} & \ldots & R_{K K}
\end{array}\right]
$$

CANALS'ta kayıp fonksiyonun minimize edilmesi amaçlanır. Minimizasyon işleminde önce $X$ değişkenleri sabit tutularak $Y$ değişkenleri minimize edilir. Sonrasında, aynı işlem $Y$ 'ler için $X$ 'ler kullanılarak tekrarlanır. Son adım olarak, nesne skorları orto-normalleştirilir. Bu adımlar, 
kayıp fonksiyon değeri en küçüklenene kadar tekrar eder (Bülbül ve Giray, 2012: 107). Analiz sonucunda, veri seti boyutları arasındaki ilişkinin derecesi kanonik korelasyon katsayısı ile yorumlanır (Özer ve Özden, 2013: 74).

\subsection{Doğrusal Olmayan Kanonik Korelasyon Analizi}

CANALS için gerekli varsayımlardan en az birinin sağlanamaması durumunda, CANALS yerine OVERALS kullanılması gerekmektedir (Süt, 2001: 15). Bu yöntemin en önemli özelliği, değişkenlerin ölçek düzeylerini araştırmacının seçebilmesine olanak vermesidir (Aydın vd., 2014: 42). OVERALS'ta, iki veya daha fazla veri seti arasındaki ilişkileri analiz etmek için kullanılır. Bu amaçla değişkenler " $k$ " adet sete ayrılır (Van de Geer, 1993: 95). Ancak, her bir sette birden fazla değişken mevcut olacağı için, setlerdeki tüm değişkenler için kayıp fonksiyonu ayrı ayrı hesaplanır (Bülbül ve Giray, 2012: 107). Bununla birlikte unutulmaması gereken asıl nokta, analizin sadece kategorik değişkenlere uygulanıyor olmasıdır. Bu sebeple, veri setinde sayısal değişken olması durumunda, değişkenlerin kategorik hale getirilmesi gerekir (Filiz ve Kolukısaoğlu, 2012: 60). Sayısal bir değişkenin OVERALS içinde kullanılabilmesi sadece bu şekilde mümkündür.

OVERALS'ta, orijinal veri alt setleri $\left(H_{k}\right)$ kullanılmaz. Bunun yerine orijinal veri setleri, gösterge matrisler $\left(G_{j}\right)$ ile değiştirilmektedir. Ayrıca, " $A_{k}$ " ağırlıkları yerine de " $Y_{j}$ " kategori sayısallaştırmaları matrisi kullanılır (Özer ve Özden, 2013: 73). OVERALS ve kayıp fonksiyonunun, literatürde farklı gösterim teknikleri bulunmaktadır. Kayıp fonksiyonu, geometrik olarak gösterilebildiği gibi ağırlıklandırma yoluyla da gösterilebilmektedir. Ağırlıklandırma yöntemine göre, bu gösterim aşağıdaki gibi olacaktır.

" $k$ " adet set için, Jan De Leeuw tarafından geliştirilmiş formül (5)'teki kayıp fonksiyonu, Van der Burg vd. tarafından formül (2) ve formül (3)'teki kısıtlara, ek bir kısıt daha eklenmesi ile formül (6)'da sunulan son halini alır (Van der Burg vd., 1988: 180-181).

$$
\min \sigma(X, Y)=\sum_{k} S S Q\left(X-\sum_{j \in J_{(k)}} G_{j} Y_{j}\right)
$$

kısıtlar,

$$
\begin{aligned}
& x^{\prime} X=n l \\
& n^{\prime} X=0 \\
& \min \sigma_{m}(X, Y)=K^{-1} \sum_{k} S S Q\left(X-\sum_{j \in J_{(k)}} G_{k j} Y_{j}\right)
\end{aligned}
$$

kısıtlar,

$$
x^{\prime} X=n l
$$

$u^{\prime} X=0$

bazı (alt) değişkenler için,

$Y_{j}=z_{j} a_{j}^{\prime}$ ve $z_{j} \in C_{j}$

Burada; 
- $J \quad: J=(1,2, \ldots, m)$ gösterge setini,

- $J_{(k)}$ : gösterge setinin bölünmüş alt setlerini,

- $k$ : set sayısını ifade etmektedir.

Formül (6)'da kategorik değerler üzerinde ölçme, ordinal ve türde ölçüm kısıtlamaları olabileceğini göstermek için genel notasyon $z_{j} \in C_{j}$ kullanılır (Van der Burg vd., 1988: 180-181). $C_{j}$ ise $h_{j}$ değişkenine uyan nominal, ordinal ya da nicel olarak ölçülen dönüşüm setini ifade etmektedir (Bülbül ve Giray, 2012: 108). Buradaki ölçme seviyesi, sadece tek bir nominal, ordinal veya nicel değer arasında ölçüm yapabileceği için değil; bir esneklik olarak birden fazla nominal değere sahip olunabileceğini belirtmek amacıyla modele eklenmektedir.

OVERALS, $n \times p$ karşılaştırma matrisinin sütunları ile onlara karşılık gelen $n \times p$ matrislerinin kanonik değişkenleri arasındaki korelasyonun toplamını maksimize eder (Thanoon vd., 2015: 93). Her bir fonksiyon için dalgalı en küçük kareler algoritması kullanılarak normalizasyon işlemi gerçekleştirilir ve minimum kılınır. Böylece, optimal çözüm değerleri elde edilmiş olur (Yazıcı vd., 2010: 506). Çözümde, eigenvalue (özdeğer) olarak ifade edilen çözüme ait uygun değer; her bir boyut için ayrı ayrı hesaplanan toplam " $p$ " adet sonuçtan ibarettir. Ortalama kayıpların 1'den çıkarılması ile boyutlarda gösterilen ilişkinin miktarı; diğer bir ifade ile özdeğeri hesaplanmış olur. Bu değer, her bir boyut için maksimum 1 ve minimum 0'dır (Van der Burg ve Bijliveld, 1993: 342). OVERALS için bir diğer önemli değer, uyum iyiliğidir. Özdeğerlerin toplamı, çözümün uyum iyiliğinin değerlendirilmesinde kullanılan ölçüttür. Uyum iyiliği, bir örneğin öngörülen bir dağılımdan gelip gelmediğini belirlemek için hesaplanan değerdir. Yani, "örnek normal bir dağılımdan gelmiştir" olarak kurulan $H_{0}$ hipotezinin, "örnek normal bir dağılımdan gelmemiştir" olarak kurulan $H_{1}$ hipotezine karşı araştırılmasıdır. (Yıldırım, 2013: 1-5; Giray, 2011: 72). OVERALS için tekli ve çoklu uyum değerleri, nesnelere göre tek ve çok kategorili koordinatların/kategori niceliklerinin uyum iyiliği olarak bilinmektedir (www.ibm.com).

Her bir satır ya da sütunun kendine has tek bir ağırlığı vardır ve buna kütle denir. Veri setlerindeki uzaklığın hesaplanmasında, dönüştürülmüş eksenler yardımıyla yapılan haritalamada; satır profil noktalarının ağırlık merkezi(centroid) uzaklıklarının kareleri bulunarak, ilgili satır ya da sütunun kütlesi ile ağırlıklandırılarak toplan ve tablonun hareketsizlik değeri elde edilir. Hareketsizlik değeri, fizik biliminden gelir ve her nesnenin kendine ait bir ağırlık merkezi olduğu kabulüyle, diğer nesneler arasındaki farksızlığı (homojenliği) temsil eder. Yani, $H_{0}$ hipotezinin kabul edildiği durumun fizik terminolojisindeki adıdır. Bu değer, satır ya da sütun değerleri arasındaki " $\chi^{2}$ " uzaklıklarının karelerinin ağırlıklı ortalamasına eşittir. Bu değer ne kadar büyükse, değişkenler arasındaki ilişki de o kadar güçlüdür. Değişkenlerin ağılık değerleri, çözümün uyum değerine olan katkılarını ne düzeyde olduğunu gösterir. Her bir satır ya da sütun profili uzayda bir nokta olarak kabul edilirse, nokta ağırlıkları eşit olduğunda centroid, noktalar kümesinin merkezinde yer alacaktır. Profillerin ağırlık değerleri farklılaştıkça, centroid yüksek ağırlıklı noktalara yakın bir pozisyon alacaktır (Giray, 2011: 51-54; Bülbül ve Giray, 2012: 111). 
OVERALS uygulamasında, kanonik korelasyon katsayısı dışında herhangi bir test değeri bulunmamaktadır (Meulman ve Heiser ile Golob ve Recker'dan aktaran Özer ve Özden, 2013: 74). ${ }^{2}$ Kanonik korelasyon katsayısı, formül (7)'deki eşitlikle hesaplanır.

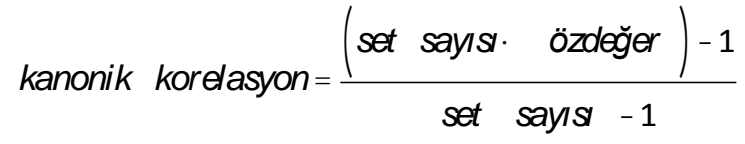

\section{Doğrusal Olmayan Kanonik Korelasyon Analizi ile Seçilmiş Demografik ve Sosyo-Kültü- rel Kavramların Değerlendirilmesi}

\subsection{Araştırmanın Amacı ve Önemi}

Bu çalışmanın amacı, Türkiye'de yaşayan bireylerin demografik özellikleri ile sosyo-kültürel kavramlara yaklaşımlarının OVERALS yöntemi ile değerlendirilmesidir. Böylelikle, değişkenler arasındaki ilişki, daha önce literatürde sık kullanılmamış olan farklı bir yöntemle ele alınmış olacaktır. Çalışma sonucunda, seçilmiş sosyo-kültürel kavramlarda görülen genel eğilimlerin Türkiye'deki bireylerin demografik özelliklerine göre değişkenlik gösterip göstermediği ve bir değişkenlik söz konusu ise bunun hangi değişkenler arasında olduğu görülebilecektir. Ayrıca, çaIışmanın bir diğer amacı da, seçilmiş sosyo-kültürel kavramlara ilişkin Türk toplumuna özgü çıktılar elde edilerek literatüre kazandırmaktır.

\subsection{Araştırmanın Evreni ve Örneklemi}

Çalışma, Türkiye' de yaşayan tüm bireylere ulaşmak mümkün olmadığından, örnekleme yöntemi tercihi ile gerçekleştirilmiştir. Bu amaçla, TÜik tarafından 2003 yılından beri uygulanan yaşam memnuniyeti anketine ait verilerin 2017 yılı mikro verileri kullanılmıştır. Yaşam memnuniyeti anketi, "bireylerin genel mutluluk algılarını, toplumsal değerlerini, temel yaşam alanlarındaki genel memnuniyetlerini ve bu alanlardaki kamu hizmetlerinden memnuniyet düzeylerini ölçmek ve bu memnuniyet düzeylerinin zaman içindeki değişimini takip etmek" amacıyla yapılmaktadır. Türkiye'nin 81 ilinde, tabakalı iki aşamalı sistematik küme örneklemesi yöntemiyle gerçekleştirilen anketin verileri, hane halkı içinde 18 ve üzeri yaştaki bireylerden yüz yüze görüşme yöntemiyle toplanmaktadır (TÜiK, 2018). Anket sorularının seçilmiş sosyo-ekonomik kavramlarla ilgili kısımları, 4'lü Likert tipi cevaplardan oluşmaktadır. Kayıp gözlemi olmayan toplam 9876 adet anket, veri seti olarak kullanılmıştır ve bu gözlem değeri, güçlü bir örneklem teşkil etmektedir. Veri setindeki iki değişken, OVERALS'a uygun ölçülmediği için revize edilmiştir. TÜiK tarafından ölçme düzeyinde toplanan "yaş" değişkeni, çalışmanın yöntemine uygun olabilmesi için ordinal hale getirilmiştir. Ayrıca, "bitirilen okul" değişkenine ait cevaplardan, 3 seçenek (genel ortaokul, mesleki veya teknik ortaokul, ilköğretim) birleştirilerek "ortaokul" seçeneği ve 2 seçenek (genel lise, mesleki ve teknik lise) birleştirilerek "lise" nominal seçeneği olarak düzenlenmiştir.

\footnotetext{
${ }^{2}$ Analiz sonucunda boyutlar arasındaki ilişkinin derecesi kanonik korelasyon katsayısı ile yorumlanır.
} 


\subsection{Veri Analizi}

Çalışmada toplam iki veri seti kullanılmıştır. Veri setlerinden ilki Set-1 olarak isimlendirilmiş olup; cinsiyet, yaş, medeni durum, çalışma durumu ve bitirilen okul olmak üzere toplam beş değişkenden oluşmaktadır. Diğer veri seti ise Set-2 olarak isimlendirilmiş ve çevre-doğa, bilim, kültür, sendika, ekonomi, siyaset, spor, moda, din, sağlık ve müzik olmak üzere 11 değişkenden oluşmaktadır.

\subsubsection{Set Değişkenlerine Ait Frekans Dağılımları}

Uygulamada kullanılan iki veri setine ait frekans dağılımları Tablo 1'de görülmektedir.

Tablo 1: Değişkenlere Ait Frekans Dağılımları

\begin{tabular}{|c|c|c|c|c|}
\hline \multicolumn{2}{|c|}{ DEĞIŞKENLER } & \multirow[t]{2}{*}{ ANKET CEVAPLARI } & \multirow{2}{*}{$\begin{array}{c}\text { FREKANS } \\
4559\end{array}$} & \multirow{2}{*}{$\begin{array}{c}\text { GEÇERLI \% } \\
46,2\end{array}$} \\
\hline Set-1 & Cinsiyet & & & \\
\hline & & Kadın & 5317 & 53,8 \\
\hline & & Toplam & 9876 & 100 \\
\hline & Yaş & $18-27$ arası & 1676 & 17 \\
\hline & & 28-47 arası & 2065 & 20,9 \\
\hline & & $38-47$ arası & 2058 & 20,8 \\
\hline & & $48-57$ arası & 1759 & 17,8 \\
\hline & & 57 üzeri & 2318 & 23,5 \\
\hline & & Toplam & 9876 & 100 \\
\hline & Medeni Durum & Hiç evlenmemiş & 1662 & 16,8 \\
\hline & & Evli & 7218 & 73,1 \\
\hline & & Boşanmış & 315 & 3,2 \\
\hline & & Eşi ölmüş & 681 & 6,9 \\
\hline & & Toplam & 9876 & 100 \\
\hline & Çalışma Durumu & Çalışıyor & 4251 & 43 \\
\hline & & Çalışıyor fakat farklı işe ilgisi var & 52 & 0,5 \\
\hline & & Çalışmıyor & 5573 & 56,5 \\
\hline & & Toplam & 9876 & 100 \\
\hline & Bitirilen okul & Bir okul bitirmedi & 1548 & 15,6 \\
\hline & & İlkokul & 3364 & 34,1 \\
\hline & & Ortaokul & 1329 & 13,5 \\
\hline & & Lise & 1885 & 19,1 \\
\hline & & 2 veya 3 yıllık yüksekokul & 535 & 5,4 \\
\hline & & 4 yıllık yüksekokul/fakülte & 1064 & 10,8 \\
\hline & & Master & 129 & 1,3 \\
\hline & & Doktora & 22 & 0,2 \\
\hline & & Toplam & 9876 & 100 \\
\hline & Çevre-Doğa & İlgiliyim & 4804 & 48,7 \\
\hline \multirow[t]{7}{*}{ Set-2 } & & Orta düzeyde ilgiliyim & 2103 & 21,3 \\
\hline & & İlgisizim & 2719 & 27,5 \\
\hline & & Fikrim yok & 250 & 2,5 \\
\hline & & Toplam & 9876 & 100 \\
\hline & Bilim & İlgiliyim & 2726 & 27,6 \\
\hline & & Orta düzeyde ilgiliyim & 1973 & 20,0 \\
\hline & & İlgisizim & 4858 & 49,2 \\
\hline
\end{tabular}


Ağustos 2019, C. 14, S. 2

\begin{tabular}{|c|c|c|c|}
\hline & Fikrim yok & 319 & 3,2 \\
\hline & Toplam & 9876 & 100 \\
\hline \multirow[t]{5}{*}{ Kültür } & İlgiliyim & 2311 & 23,4 \\
\hline & Orta düzeyde ilgiliyim & 1943 & 19,7 \\
\hline & İlgisizim & 5306 & 53,7 \\
\hline & Fikrim yok & 316 & 3,2 \\
\hline & Toplam & 9876 & 100 \\
\hline \multirow[t]{5}{*}{ Sendika } & İlgiliyim & 630 & 6,4 \\
\hline & Orta düzeyde ilgiliyim & 603 & 6,1 \\
\hline & İlgisizim & 8198 & 83,0 \\
\hline & Fikrim yok & 445 & 4,5 \\
\hline & Toplam & 9876 & 100 \\
\hline \multirow[t]{5}{*}{ Ekonomi } & İlgiliyim & 2677 & 27,1 \\
\hline & Orta düzeyde ilgiliyim & 2202 & 22,3 \\
\hline & İlgisizim & 4692 & 47,5 \\
\hline & Fikrim yok & 305 & 3,1 \\
\hline & Toplam & 9876 & 100 \\
\hline \multirow[t]{5}{*}{ Siyaset } & İlgiliyim & 1896 & 19,2 \\
\hline & Orta düzeyde ilgiliyim & 2118 & 21,4 \\
\hline & İlgisizim & 5582 & 56,5 \\
\hline & Fikrim yok & 280 & 2,9 \\
\hline & Toplam & 9876 & 100 \\
\hline \multirow[t]{5}{*}{ Spor } & İlgiliyim & 2557 & 25,9 \\
\hline & Orta düzeyde ilgiliyim & 1657 & 16,8 \\
\hline & İlgisizim & 5404 & 54,7 \\
\hline & Fikrim yok & 258 & 2,6 \\
\hline & Toplam & 9876 & 100 \\
\hline \multirow[t]{5}{*}{ Moda } & İlgiliyim & 1013 & 10,3 \\
\hline & Orta düzeyde ilgiliyim & 1362 & 13,8 \\
\hline & İlgisizim & 7231 & 73,2 \\
\hline & Fikrim yok & 270 & 2,7 \\
\hline & Toplam & 9876 & 100 \\
\hline \multirow[t]{5}{*}{ Din } & İlgiliyim & 6595 & 66,8 \\
\hline & Orta düzeyde ilgiliyim & 2132 & 21,6 \\
\hline & İlgisizim & 1083 & 10,9 \\
\hline & Fikrim yok & 66 & 0,7 \\
\hline & Toplam & 9876 & 100 \\
\hline \multirow[t]{5}{*}{ Sağlık-Konusu } & İlgiliyim & 6606 & 66,9 \\
\hline & Orta düzeyde ilgiliyim & 1989 & 20,1 \\
\hline & İlgisizim & 1179 & 12,0 \\
\hline & Fikrim yok & 102 & 1,0 \\
\hline & Toplam & 9876 & 100 \\
\hline \multirow[t]{5}{*}{ Müzik } & İlgiliyim & 3968 & 40,2 \\
\hline & Orta düzeyde ilgiliyim & 2384 & 24,1 \\
\hline & Illgisizim & 3360 & 34,0 \\
\hline & Fikrim yok & 164 & 1,7 \\
\hline & Toplam & 9876 & 100 \\
\hline
\end{tabular}




\subsubsection{Kanonik Korelasyon Analizi Sonuçları ve Bulguları}

Çalışmanın bu kısmında bölüm 4.3.1'de tanımlanmış olan değişkenler için SPSS 24.0 paket programı ile OVERALS gerçekleştirilmiştir. Analiz sonuçlarına 13 iterasyonda ulaşılmıştır.

Tablo 2: Genel Uyum Değerleri

\begin{tabular}{|c|c|c|c|c|}
\hline & & \multicolumn{2}{|c|}{ BOYUTLAR } & \multirow[t]{2}{*}{ TOPLAM } \\
\hline & & 1 & 2 & \\
\hline \multirow{3}{*}{ Kayıp Fonksiyonu } & Set-1 & 0,152 & 0,256 & 0,408 \\
\hline & Set-2 & 0,152 & 0,255 & 0,407 \\
\hline & Ortalama & 0,152 & 0,256 & 0,408 \\
\hline Özdeğer & & 0,848 & 0,744 & \\
\hline Uyum & & & & 1,592 \\
\hline
\end{tabular}

Tablo 2'de çözümün ne kadar iyi olduğunu gösteren kayıp fonksiyonu ve uyum değerleri görülmektedir. Bu değerlere göre, ortalama kayıp değeri 1.boyut için 0,152 ve 2.boyut için 0,256 'dır. Bu değerlerin, ayrı ayrı "1" değerinden çıkarılması ile özdeğerler hesaplanır. Böylece, 1.boyut ve 2 .boyut için özdeğerler sırasıyla 0,848 ve 0,744 olarak elde edilir. Özdeğer, her bir diskriminant fonksiyonun göreli etkinliği hakkında bilgi vermektedir. Bu değer, gruplar arası korelasyona eşdeğer olduğundan OVERALS için en yararlı ölçümdür (www.ibm.com). OVERALS'ta uyum, en fazla kullanılan set sayısı kadardır ve bu çalışmada iki set olduğu için en yüksek uyum olabilirliği 2'dir. Tablo 2'ye göre, modelin toplam uyumu 1,592 olarak hesaplandığından \%79,6 gibi $(1,592 / 2)$ yüksek bir değere sahiptir. Bununla birlikte, Set-1 gerçek uyum değeri olan 1,592 'nin \%53,3'ünü $(0,848 / 1,592)$ açıklayabiliyorken; Set-2 gerçek uyumun \%46,7'lik kısmını $(0,744 / 1,592)$ açıklayabilmektedir.

Formül (7) kullanılarak, kanonik korelasyon katsayıları elde edilir. Kanonik korelasyon katsayıları, 1 .boyutta 0,696 ve 2 .boyutta 0.488 olarak hesaplanmıştır. Yani, birinci boyuta göre demografik değişkenler ile seçilmiş sosyo-kültürel değişkenler arasında pozitif yönde \%69,6 seviyesinde bir ilişki bulunurken; ikinci boyutta bu ilişki pozitif yönde $\% 48,8$ seviyesindedir.

Tablo 3: Ağırlık Değerleri ve Bileşen Yüklemeleri

\begin{tabular}{clcccc}
\hline & Değişkenler & \multicolumn{2}{c}{ AĞIRLIK DEĞERLERi } & \multicolumn{2}{c}{ BiLEŞEN YÜKLEMELERI } \\
& & \multicolumn{2}{c}{ BOYUT } & \multicolumn{2}{c}{ BOYUT } \\
\hline \hline \multirow{2}{*}{ Set-1 } & Cinsiyet & 1 & 2 & 1 & 0,753 \\
& Yaş & $-0,177$ & 0,770 & $-0,355$ & $-0,393$ \\
& Medeni Durum & $-0,071$ & $-0,257$ & $-0,451$ & $-0,258$ \\
& Çalışma Durumu & $-0,150$ & $-0,150$ & $-0,491$ & 0,277 \\
& Bitirilen Okul & $-0,043$ & 0,045 & $-0,374$ & 0,104 \\
\hline \multirow{2}{*}{ Set-2 Çevre-Doğa } & 0,753 & 0,114 & 0,881 & 0,079 \\
& Bilim & 0,063 & 0,053 & $-0,056$ & $-0,038$ \\
& Kültür & $-0,386$ & $-0,030$ & $-0,788$ & $-0,187$ \\
& Sendika & $-0,208$ & $-0,359$ & $-0,730$ & 0,181 \\
& Ekonomi & $-0,030$ & 0,185 & $-0,337$ & 0,374 \\
& Siyaset & $-0,094$ & 0,433 & $-0,537$ & 0,290 \\
& Spor & $-0,029$ & 0,200 & $-0,468$ & 0,213 \\
& Moda & $-0,287$ & 0,389 & $-0,695$ & $-0,496$ \\
& Din & $-0,074$ & $-0,606$ & $-0,481$ & $-0,003$ \\
& Sağlık-Konu & $-0,010$ & 0,238 & $-0,071$ \\
& Müzik & 0,155 & $-0,086$ & $-0,097$ & $-0,192$ \\
\hline
\end{tabular}


Tablo 3'te kanonik değişkenlerin elde edilmesinde, değişkenlerin her bir boyuttaki uyuma olan katkılarını gösteren ağırlık değerleri ve bileşen yükleri görülmektedir. Bu değerler, veri setleri için hangi değişkenlerin daha yüksek etki (veya katkı) gücüne sahip olduğu hakkında bilgi vermektedir. Eğer, bir değişkenin önündeki katsayı pozitif ise, ilgili değişken ile diğer değişkenler arasında aynı yönde; negatif ise ters yönde korelasyon mevcuttur. Tablo 3 incelendiğinde, 1. boyutun uyum değeri için en yüksek katkıyı Set-1'de bulunan "bitirilen okul" $(0,753)$ değiş̧keni sağlarken; bunu Set-2'deki "bilim" $(-0,386)$ değişkeni takip etmektedir. 2. boyutun uyum değeri için en yüksek katkıyı Set-1'deki "cinsiyet" $(0,770)$ değişkeni sağlamıştır. Ardından ise sırası ile Set-2'deki “moda" $(-0,606)$, "ekonomi" $(0,433)$, "spor" $(0,389)$ ve "kültür" $(-0,359)$ değişkenleri gelmektedir.

Bileşen yüklemeleri olarak adlandırılan değişkenlerin gölge koordinatları, dönüştürülmüş değişkenler ve nesne puanları arasındaki korelasyona karşılık gelir (Van der Burg vd., 1994: 153). Bu koordinatların analitik düzlemdeki gösterimi Şekil 2'de görülmektedir.

Şekil 2: Bileşen Yüklemeleri

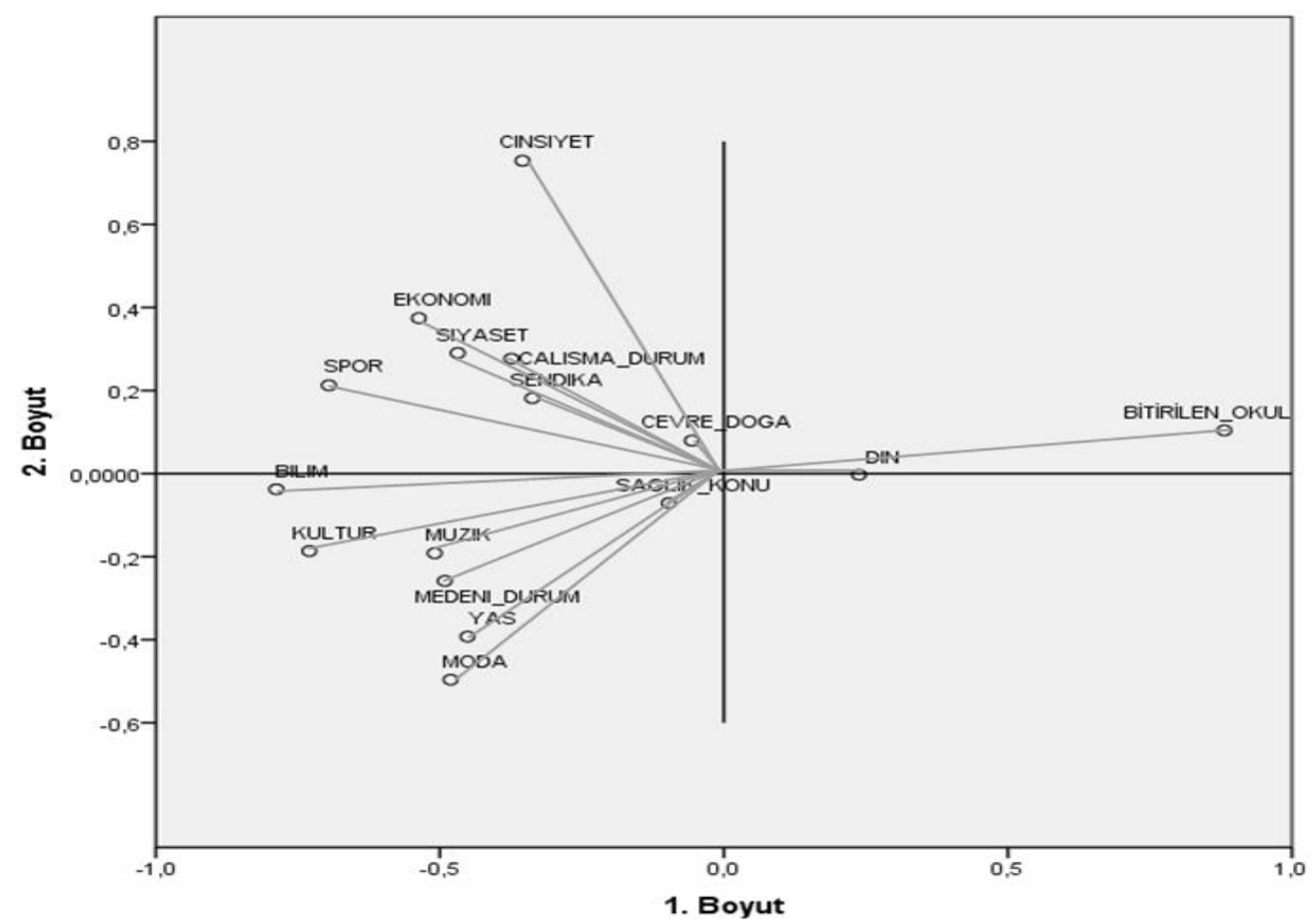

Bileşen yüklemeleri grafiğinde görülen değişkenler, orijine ne kadar uzaksa, o değişken analiz için o kadar önemlidir. Genel olarak bunun yorumlanabilmesi için her bir değişkenden orijine doğru bir vektör çizilir. Eksik veri olmadığı hallerde, bileşen yüklemeleri nicel değişkenler ile nesne puanları arasındaki Pearson korelasyonlarına denk sonuçlar verir. Bir başka ifade ile değişkenler arasındaki ilişkinin görülmesine olanak tanır. Orijinden her bir değişken noktasına olan uzaklık, ilgili değişkenin önemini tahmin eder (IBM Knowledge Center, 2018). Bileşen yüklemelerinde "bilim, bitirilen okul ve cinsiyet" değişkenlerinin önemlerinin, açık bir şekilde diğer değişkenlere nazaran daha yüksek olduğu görülmektedir. 
Tablo 4: Tekli ve Çoklu Uyum Gösterimi

\begin{tabular}{llccccccccc}
\hline & Değişkenler & \multicolumn{3}{c}{ ÇOKLU UYUM } & \multicolumn{3}{c}{ TEKLi UYUM } & \multicolumn{3}{c}{ TEKLi KAYIP } \\
& & \multicolumn{1}{c}{ BOYUT } & \multicolumn{4}{c}{ BOYUT } & \multicolumn{3}{c}{ BOYUT } \\
& & 1 & 2 & Ort. & 1 & 2 & Ort. & 1 & 2 & Ort. \\
\hline \hline Set-1 & Cinsiyet & 0,031 & 0,593 & 0,624 & 0,031 & 0,593 & 0,624 & 0,000 & 0,000 & 0,000 \\
& Yaş & 0,006 & 0,066 & 0,072 & 0,005 & 0,066 & 0,071 & 0,001 & 0,000 & 0,001 \\
& Medeni Durum & 0,023 & 0,023 & 0,045 & 0,023 & 0,023 & 0,045 & 0,000 & 0,000 & 0,000 \\
& Çalışma Durumu & 0,002 & 0,002 & 0,004 & 0,002 & 0,002 & 0,004 & 0,000 & 0,000 & 0,000 \\
& Bitirilen Okul & 0,567 & 0,013 & 0,580 & 0,567 & 0,013 & 0,580 & 0,000 & 0,000 & 0,000 \\
\hline Set-2 & Çevre-Doğa & 0,004 & 0,003 & 0,007 & 0,004 & 0,003 & 0,007 & 0,000 & 0,000 & 0,000 \\
& Bilim & 0,149 & 0,001 & 0,150 & 0,149 & 0,001 & 0,150 & 0,000 & 0,000 & 0,000 \\
& Kültür & 0,043 & 0,129 & 0,172 & 0,043 & 0,129 & 0,172 & 0,000 & 0,000 & 0,000 \\
& Sendika & 0,001 & 0,034 & 0,035 & 0,001 & 0,034 & 0,035 & 0,000 & 0,000 & 0,000 \\
& Ekonomi & 0,009 & 0,187 & 0,196 & 0,009 & 0,187 & 0,196 & 0,000 & 0,000 & 0,000 \\
& Siyaset & 0,001 & 0,040 & 0,041 & 0,001 & 0,040 & 0,041 & 0,000 & 0,000 & 0,000 \\
& Spor & 0,082 & 0,152 & 0,234 & 0,082 & 0,152 & 0,234 & 0,000 & 0,000 & 0,000 \\
& Moda & 0,006 & 0,367 & 0,373 & 0,005 & 0,367 & 0,373 & 0,000 & 0,000 & 0,000 \\
& Din & 0,024 & 0,000 & 0,024 & 0,024 & 0,000 & 0,024 & 0,000 & 0,000 & 0,000 \\
& Sağlık-Konu & 0,008 & 0,007 & 0,016 & 0,008 & 0,007 & 0,016 & 0,000 & 0,000 & 0,000 \\
& Müzik & 0,014 & 0,024 & 0,037 & 0,014 & 0,024 & 0,037 & 0,000 & 0,000 & 0,000 \\
\hline
\end{tabular}

Tablo 4'te tekli ve çoklu uyum değerleri görülmektedir. Bu tablo değerlendirilirken tekli ve çoklu kayıp sütunlarının, toplam sütunundaki değerlere göre ölçek düzeylerinde bir değişiklik yapılıp yapıımayacağına göre karar verilir. Tekli ve çoklu kayıp değerleri arasında büyük farklar varsa tekli nominal değişken, çoklu nominal hale getirilmelidir. Bu çalışmada tekli ve çoklu uyum değerleri arasında farka rastlanmamaktadır. Ayrıca, burada yüksek değerler söz konusu ise ölçek düzeylerinde değişikliğe gidilmesi analiz için daha uygun olacaktır. Bununla birlikte, değişkenler içerisinde ayırma gücü yüksek değişkenlerin belirlenmesinde de uyum değerleri yol göstericidir. Bu çalışmada, elde edilen verilere göre; cinsiyet, bitirilen okul, moda, spor, ekonomi, bilim ve kültür kavramları ayırma gücü bakımından daha belirgin değişkenlerdir.

Şekil 3'te görülen ağırlık merkezi (centroids) sonuçlarına göre, çalışmada dikkat çeken sonuçlar aşağıdaki gibi sıralanmıştır.

- Bir işte çalışmayan bireylerin ekonomi, siyaset, spor sosyo-kültürel kavramlarına karşı ilgisiz oldukları tespit edilmiştir.

- Kadınların çok güçlü bir küme oluşturmada ekonomi, siyaset, spor sosyo-kültürel kavramlarına karşı ilgisiz oldukları tespit edilmiştir.

- Eğitim durumu lise üzeri olan bireylerin, müzik kavramına ilgilerinin olduğu tespit edilmiştir.

- Herhangi bir okul bitirmemiş olan bireylerin, genelde araştırma için seçilmiş sosyo-kültürel kavramlara karşı duyarsız oldukları tespit edilmiştir.

- Bitirilen okul türü ile moda kavramına ilgili olmak arasında pozitif yönde bir ilişki olduğu tespit edilmiştir. 
- 18-27 yaş grubunda olan bireyler, moda kavramına orta ve yüksek düzeyde ilgi gösterirken; 48 yaş üzerinde olan bireyler ile moda kavramına ilgi arasında ters yönlü bir ilişki olduğu tespit edilmiştir.

- Yaşı 57 üzerinde ve ilkokul mezunu olan bireylerin müzik, kültür, bilim sosyo-kültürel kavramlara karşı ilgisiz oldukları tespit edilmiştir.

- Herhangi bir işte çalışmayan bireylerin siyaset, spor ve ekonomi sosyo-kültürel kavramlarına karşı ilgisiz oldukları tespit edilmiştir.

- Dini kavramlara ilgisi olmayan bireylerin, çevre-doğa sosyo-kültürel kavramına karşı yüksek düzeyinde ilgi sahibi oldukları tespit edilmiştir.

- Genel olarak tüm seçilmiş sosyo-kültürel kavramlara orta ve yüksek düzeyde ilgisi olan bireylerin, eğitim düzeyi lise ve üzeri olan katılımcılardan oluştuğu tespit edilmiştir.

- Siyaset kavramına orta ve yüksek düzeyde ilgili olanların, yüksek düzeyde erkeklerden oluştuğu tespit edilmiştir.

- Kadınların sendika sosyo-kültürel kavramına karşı genel olarak ilgilerinin düşük olduğu görülürken; erkeklerin bu kavramlara karşı ilgilerinin yüksek olduğu tespit edilmiştir.

\section{Şekil 3: Ağırlık Merkezleri (Centroids)}

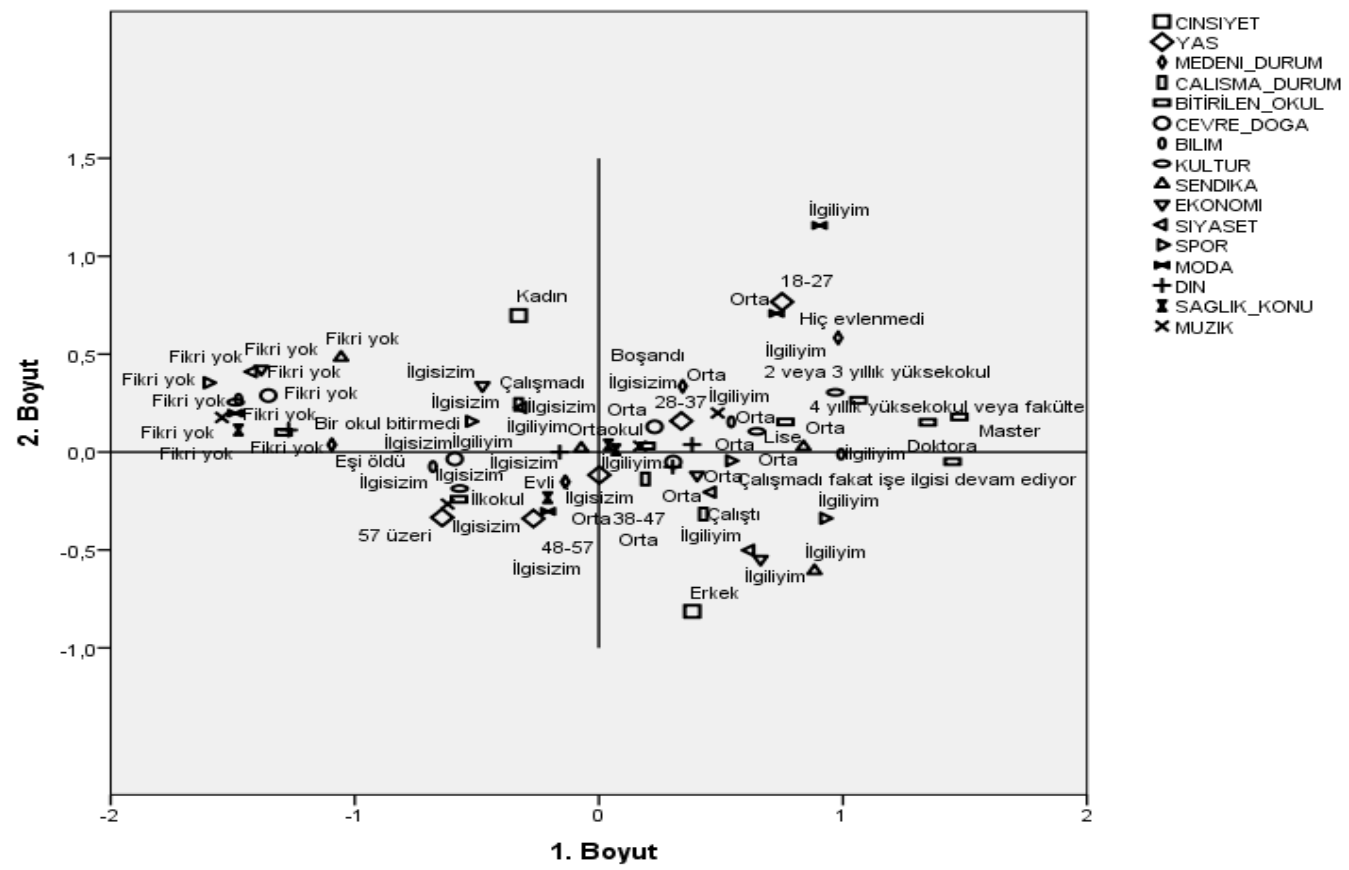

\section{Sonuç}

OVERALS, kategorik değişkenlerden oluşan veri setleri arasında doğrusal olmayan kanonik korelasyonun hesaplanmasına olanak sağlayan bir tekniktir. Araştırmacılara, ağılık merkezleri yardımıyla değişkenler arasında ortaya çıkan homojenliklerin kolaylıkla görülmesi ya da heterojen grupların tanımlanması gibi kolaylıklar sağlamaktadır. Bu çalışmada, Gifi terminolojisinin genelleştirilmiş son hali OVERALS ile nominal ve ordinal düzeyde ölçülmüş iki veri seti arasındaki 
ilişkiler incelenmiştir. Bunun için, TÜiK tarafından her yıl gerçekleştirilen Yaşam Memnuniyeti Anketi'nin 2017 yılı mikro verileri kullanılmıştır. Çalışma sonucunda, seçilmiş sosyo-kültürel kavramlar ile demografik özellikler arasındaki ilişkinin, kanonik korelasyon katsayısına göre \%70 olduğu hesaplanmıştır. Türkiye'de gruplar arası farklılığa neden olan değişkenlerin başında demografik değişkenlerden cinsiyet ve bitirilen okul; sosyo-kültürel değişkenlerden ise moda, ekonomi, bilim, kültür ve spor gelmektedir. Diğer sosyo-kültürel kavramların ve demografik özelliklerin istatistiksel olarak ayırt edici güçte farklılıklarının olmadığı belirlenmiştir. OVERALS yönteminin, centroids sayesinde kategorik değişkenler arasındaki farklılaşma ve ilişkileri kolaylıkla gösterme avantajı olmasına rağmen, bulguların test edilememesi gibi bir de dezavantajı vardır. Bu durum, $\chi^{2}$-bağımsızlık testi gibi parametrik olmayan hipotez testleri, sıralı logit, multinominal logit, kategorik regresyon analizi vb. yöntemlerle giderilebilmektedir. 


\section{Kaynaklar}

Altaş, Dilek; Giray, Selay (2013), “Dünyadaki En Önemli Sorun Algısının Optimal Ölçeklemeli Çok Değişkeni İstatistiksel Yöntemler ile İncelenmesi”, Öneri Dergisi, C. 10: 135-142.

Aydın, Serdar; Görmüş, Alparslan Ş.; Altıntop, M.Y. (2014), “Öğrencilerin Memnuniyet Düzeyleri İle Demografik Özellikleri Arasındaki İlişkinin Doğrusal Olmayan Kanonik Korelasyon Analizi ille İncelenmesi: Meslek Yüksekokulu'nda Bir Uygulama", Аівய̈ Sosyal Bilimler Enstitüsü Dergisi, C.14, S.1: 35-58.

Bayram, Nuran; Ertaş, Sacit (2001), Tüketim Harcamaları Davranış Biçimi: PRINCALS ve OVERALS Yaklaşımı. http://idari.cu.edu.tr/sempozyum/bil62.htm (Erişim: 15.01.2015).

Bülbül, Şahamet; Giray, Selay (2012), “iş ve özel yaşam (İş Dışı Yaşam) Memnuniyeti Arasındaki ilişki Yapısının Doğrusal Olmayan Kanonik Korelasyon Analizi ile İncelenmesi”, Anadolu Üniversitesi Sosyal Bilimler Dergisi, C. 12, S. 4: 101114.

Çankaya, Soner (2005), Kanonik Korelasyon Analizi ve Hayvancılıkta Kullanımı, Çukurova Üniversitesi Fen Bilimleri Enstitüsü, Yayınlanmış Doktora Tezi.

De Leeuw, Jan (1984), The Gifi System of Nonlinear Multivariate Analysis, Data Analysis and Informatics-III, Elsevier Science Publishers. B. V., http://gifi.stat.ucla.edu/janspubs/1984/chapters/deleeuw_c_84c.pdf, (Erişim: 14.07.2018).

De Leeuw, Jan; Mair, Patrick (2009), "Gifi Methods For Optimal Scaling in R: The Package HOMALS", Journal Of Statistical Software, Vol. 31, No. 4: 1-21.

De Leeuw, Jan; Mair, Patrick; Groenen, P.(2016), "Multivariate Analysis With Optimal Scalling", http://gifi.stat.ucla.edu/gifi/_book/_main.pdf (Erişim: 14.07.2018).

Dong, Li.; Zhang, Yangsong, Zhang; Rui; Z. X.; Diankun, G.; Valdes-Sosa, P. A.; Xu, P., Luo, C.; Yao, D.(2015), “Characterizing Nonlinear Relationships in Functional Imaging Data Using Eigenspace Maximal Information Canonical Correlation Analysis (Emicca)", Neuroimage, Vol. 109: 388-401.

Filiz, Zeynep; Kolukusaoğlu, Sıdıka (2012), “Doğrusal Olmayan Kanonik Korelasyon Analizi ve Bir Uygulama” Int. Journal of Management Economics And Business (Uluslararası Yönetim Iktisat ve Işsletme Dergisi), Vol. 8, No. 16: 59-75.

Frie, Kirsten Grosse; Janssen, Christian (2009), "Social Inequality, Lifestyles and Health-A Non-Linear Canonical Correlation Analysis Based On The Approach Of Pierre Bourdieu", International Journal Of Public Health, Vol. 54, No. 4: 213-221.

Gifi, Albert (1989), “Algorithm Descriptions For Anacor Homals PRINCALS and OVERALS”, Research Report, Rr. 89-01.

Giray, Selen (2011), Doğrusal Olmayan Kanonik Korelasyon Analizi ve Yaşam Memnuniyeti Üzerine Bir Uygulama, Marmara Üniversitesi Sosyal Bilimler Enstitüsü, Yayınlanmış Doktora Tezi.

Girginer, Nuray; Kaygısız, Zeynep; Yalama, A. (2007), “Doğrusal Olmayan Kanonik Korelasyon Analizi İle İstatistiğe Yönelik Tutumlarda Üniversite Öğrencileri Arasındaki Bireysel Farklılıkların İncelenmesi”, İstanbul Üniversitesi İktisat Fakültesi Ekonometri ve Istatistik Dergisi, S. 6: 29-40.

Hsieh, William W. (2001), "Nonlinear Canonical Correlation Analysis of The Tropical Pacific Climate Variability Using A Neural Network Approach", Journal Of Climate, Vol. 14: 2528-2539.

Hsieh, Yen-Ping; Huang, Ying-Chia; Lan, Shou-Jen; Ho, Ching-Sung (2017), "Factors Related to The Decision-Making For Moving The Older Adults into Long-Term Care Facilities in Taiwan", Geriatrics \& Gerontology International, Vol.17, No. 9: 1319-1327.

http://www.mvstats.com/downloads/supplements/canonical_correlation_7e.pdf. (Erişim: 14.01. 2015).

http://www.tuik.gov.tr/PreHaberBultenleri.do?id=27590 (Erişim Tarihi: 25.12.2018),

https://www.ibm.com/support/knowl-edgecenter/en/ss/vmb_24.0.0/spss/tutorials/disc-rim_bankloan_e-igen.html (Erişim: 12.09.2018).

Keskin, Sıddık; Özsoy, Abdullah Nuri (2004), "Kanonik Korelasyon Analizi ve Bir Uygulama”, Tarım Bilimleri Dergisi, C. 10, S. 1: 67-71.

Koşkan, Özgür; Önder, Elif Gül; Şen, N.(2011), “Değişken Setleri Arası Illişkinin Tahmini İçin Kanonik Korelasyon Analizinin Kullanımı”, Iğdır Üniversitesi Fen Bilimleri Enstitüsü Dergisi (Iğdır University Journal of The Institute of Science and Technology), Vol. 1, No. 2: 117-123.

Meyers, Lawrance S.; Gamst, Glenn; Guarino, A.J. (2009), Data Analysis Using-SAS Enterprise Guide, Cambridge: Cambridge University Press. 


\section{Eskişehir Osmangazi Üniversitesi IïBF Dergisi}

Michalidis, George; De Leeuw, Jan (1998), "The Gifi System of Descriptive Multivariate Analysis", Statistical Science, Vol. 12, No. 4: 307-336.

Özer, Osman Orhan; Özden, Altuğ (2013), “Ege Bölgesi Yaş Meyve ve Sebze İhracatçılarının Bireysel Farklılıklarının İncelenmesi", Tarım Ekonomisi Dergisi, C. 19, S. 1: 71-79.

Sertbarut, Pervin (2010),Doğrusal ve Doğrusal Olmayan Kanonik Korelasyon ve Bankacılık Sektöründe Uygulanması, Hacettepe Üniversitesi Fen Bilimleri Enstitüsü, Yayınlanmış Yüksek Lisans Tezi.

Suner, Aslı; Çelikoğlu, Can Cengiz (2010), "Toplum Tabanlı Bir Çalışmada Çoklu Uygunluk Analizi ve Kümeleme Analizi ile Sağlık Kurumu Seçimi”, Dokuz Eylül Üniversitesi Iktisadi ve Idari Bilimler Fakültesi Dergisi, C. 25, S. 2: 43-55.

Süt, Necdet (2001), Doğrusal Olmayan Kanonik Korelasyon Analizi ve Bir Uygulama, Trakya Üniversitesi Sağlık Bilimleri Enstitüsü, Yayınlanmış Yüksek Lisans Tezi.

Thanoon, Y. Thanoon; Adnan, Robiah; Saffari,S. E.(2015) “Generalized Nonlinear Canonical Correlation Analysis with Ordered Categorical and Dichotomous Data", Jurnal Teknologi, Vol. 75, No. 1: 91-99.

Thompson, Bruce (1984), Canonical Correlation Analysis-Used and Interpretation, California: Sage Publications.

Van der Burg, Eeke, De Leeuw, Jan; Dijksterhuis, Garmt (1994), “OVERALS-Nonlinear Canonical Correlation with k Sets of Variables", Computational Statistics \& Data Analysis, Vol. 18: 141-163.

Van der Burg, Eeke; Bijliveld Catrien C.J.H., (1993), "Longitudinal k-Sets Analysis Using a Dummy Time Variable", Qüestiio, Vol. 17: 339-351.

Van der Burg, Eeke; De Leeuw, Jan; Verdegaal, R.(1988), “Homogeneity Analysis With k Sets of Variables: An Alternating Least Squares Method With Optimal Scaling Features”, Psychometri, Vol. 53, No. 2: 177- 197.

Van Der Heijden, Peter G.M.; Van Buuren, Stef (2016), "Looking Back At The Gifi System of Nonlinear Multivariate Analysis", Journal Of Statistical Software, Vol. 74, No. 4: 1-8.

Yazıcı, Ayşe Canan; Öğüş, Ersin; Ankaralı, Handan; Gürbüz, Fikret (2010), “An Application of Nonlinear Canonical Correlation Analysis on Medical Data", Turkish Journal of Medical Science, Vol. 40, No. 3: 503-510.

Yıldırım, Nurcan (2013), Normal Dağılım İçin Uyum lyiliği Testleri ve Bir Simülasyon Çalışması, Gazi Üniversitesi Fen Bilimleri Enstitüsü, Yayınlanmış Yüksek lisans Tezi.

Yoshida, Kosuke; Yoshimoto, Junichiro; Doya, K. (2017), "Sparse Kernel Canonical Correlation Analysis for Discovery of Nonlinear Interactions in High-Dimensional Data", BMC Bio Informatics, Vol. 18, No. 1: 1-11. 